Review

\title{
Coating and Surface Treatments on Orthodontic Metallic Materials
}

\section{Santiago Arango ${ }^{1,2, *}$, Alejandro Peláez-Vargas ${ }^{1}$ and Claudia García ${ }^{3}$}

1 Faculty of Dentistry, Universidad Cooperativa de Colombia, Medellín, Colombia;

E-Mail: alejandro.pelaezv@campusucc.edu.co

2 Universidad Nacional de Colombia, Medellín, Colombia

3 Ceramics and Glasses Group, Faculty of Sciences, Universidad Nacional de Colombia, Medellín, Colombia; E-Mail: cpgarcia@unal.edu.co

* Author to whom correspondence should be addressed; E-Mail: santiago.arango@campusucc.edu.co; Tel.: +57-4-3132636; Fax: +57-4-2702627.

Received: 12 November 2012; in revised form: 14 December 2012 / Accepted: 21 December 2012 / Published: 27 December 2012

\begin{abstract}
Metallic biomaterials have been extensively used in orthodontics throughout history. Gold, stainless steel, cobalt-chromium alloys, titanium and its alloys, among other metallic biomaterials, have been part of the orthodontic armamentarium since the twentieth century. Metals and alloys possess outstanding properties and offer numerous possibilities for the fabrication of orthodontic devices such as brackets, wires, bands, ligatures, among others. However, these materials have drawbacks that can present problems for the orthodontist. Poor friction control, allergic reactions, and metal ionic release are some of the most common disadvantages found when using metallic alloys for manufacturing orthodontic appliances. In order to overcome such weaknesses, research has been conducted aiming at different approaches, such as coatings and surface treatments, which have been developed to render these materials more suitable for orthodontic applications. The purpose of this paper is to provide an overview of the coating and surface treatment methods performed on metallic biomaterials used in orthodontics.
\end{abstract}

Keywords: coating; surface treatment; titanium alloys; stainless steel; orthodontic metals 


\section{Introduction}

Metallic biomaterials are widely used today in dental practices around the world. Metals and alloys offer unique physical properties, such as excellent electrical and thermal conductivity, and outstanding mechanical properties. Some metals can be used as passive substitutes of hard tissues (dental implants) and fracture healing aids (bone plates and screws) due to their aforementioned exceptional mechanical properties and corrosion resistance. Others play more active roles, such as orthodontic brackets and archwires [1]. The most extensively used metallic biomaterials are commercially pure titanium and its alloys, stainless steel, and chromium-cobalt alloys [2].

Titanium and its alloys have been used in medicine and dentistry for decades. Different specialties within the dental profession take advantage of this material. Titanium alloyed with elements such as nickel, molybdenum or copper has widespread use in orthodontics [3]; the combinations of this metal with others, such as aluminium or vanadium, are used in oral rehabilitation, implantology $[1,4,5]$, and maxillofacial surgery [6-8].

Titanium is an allotropic material that exists in two forms: a hexagonal closed pack structure $(\alpha-\mathrm{Ti})$ up to $882{ }^{\circ} \mathrm{C}$ and a body-centered cubic structure $(\beta$-Ti) above this temperature. The $\alpha$-phase is characterized by high strength and low weight. Aluminium is one of the most common elements used to stabilize such a phase for titanium alloys used as biomaterials. The $\beta$-phase shows high corrosion resistance. Molybdenum and vanadium, among other elements, are used to stabilize this phase [1]. Titanium can be classified as unalloyed or commercially pure (cp) titanium and titanium alloys. Commercially pure titanium can be further classified into four grades (1 through 4) depending on titanium and impurity contents; the most common titanium alloy used for dental applications is Ti6Al4V, with aluminium and vanadium being the main alloying elements [1]. Commercially pure titanium grade 4 and Ti6Al4V alloy are the most widely used types for manufacturing orthodontic brackets. Additional titanium alloys, such as NiTi (nickel-titanium) and CuNiTi (copper-nickel-titanium) are used for fabricating orthodontic wires [9]. Currently, NiTi alloys have a composition of $55 \%$ nickel and $45 \%$ titanium [10], 5\%-6\% copper is added to NiTi alloys with the goal of increasing strength and reducing energy loss, $0.5 \%$ chromium is added to CuNiTi alloys to reduce the stress transformation temperature to $27^{\circ} \mathrm{C}$ [11]. Table 1 shows the chemical composition of commercially pure titanium and Ti6Al4V alloy.

Table 1. Chemical composition of titanium and its alloys (\% mass/mass) [12,13].

\begin{tabular}{cccccc}
\hline Element & Grade 1 & Grade 2 & Grade 3 & Grade 4 & Ti6Al4V \\
\hline Nitrogen & 0.03 & 0.03 & 0.05 & 0.05 & 0.05 \\
Carbon & 0.08 & 0.08 & 0.08 & 0.08 & 0.08 \\
Hydrogen & 0.015 & 0.015 & 0.015 & 0.015 & 0.0125 \\
Iron & 0.20 & 0.30 & 0.30 & 0.50 & 0.25 \\
Oxygen & 0.18 & 0.25 & 0.35 & 0.40 & 0.13 \\
Aluminium & -- & -- & -- & -- & $5.50-6.50$ \\
Vanadium & -- & -- & -- & -- & $3.50-4.50$ \\
& Titanium & & & Balance & \\
\hline
\end{tabular}


Stainless steel is an alloy that is commonly used in orthodontics for manufacturing brackets, wires, ligatures, bands, and other applications [3,14]. This alloy is composed of iron and carbon and contains smaller quantities of nickel, chromium, and other elements that impart the property of resisting corrosion [15]. Cobalt-chromium alloys are mainly used in rehabilitation [16] and orthodontics [3]. The chromium content in this alloy enhances its corrosion resistance [1]. There are five types of stainless steel alloys depending on microstructure and chemical composition: austenitic, martensitic, ferritic, duplex (austenitic-ferritic) and precipitation-hardening [17]. Austenitic stainless steels are the most widely used types for manufacturing orthodontic brackets and archwires [18-20]. Table 2 shows the chemical composition and AISI (American Iron and Steel Institute) grades of stainless steel alloys.

Table 2. Chemical composition and AISI grades of stainless steel alloys (wt.\%) [1,18,21-26].

\begin{tabular}{ccccccccccc}
\hline Alloy/Element & AISI series & C & Cr & Ni & Mo & Mn & S & P & Si & Fe \\
\hline Ferritic & 4 XX & 0.12 & $12-29$ & $<2$ & -- & 1 & $<0.03$ & $<0.04$ & $<1$ & \\
Martensitic & $4 X X$ & $0.15-1$ & $12-18$ & $>0.75$ & -- & $<1$ & $<0.03$ & $<0.04$ & $<1$ & \\
Austenitic & $3 X X$ & $0.02-0.05$ & $17-20$ & $8-12$ & $2(316-316 \mathrm{~L})$ & $<2$ & $<0.015$ & $<0.04$ & $<1$ & Balance \\
Duplex & 2205 & $<0.03$ & $18-26$ & $4.5-6.5$ & $2.5-3.5$ & $<2$ & $<0.02$ & $<0.03$ & $<1$ & \\
$\begin{array}{c}\text { Precipitation- } \\
\text { hardening }\end{array}$ & $630(17-4)$ & 0.07 & $15.5-17.5$ & $3-5$ & 0.06 & 1.5 & 0.02 & 0.04 & 0.7 & \\
\hline
\end{tabular}

As already stated, metals and alloys have remarkable physical and mechanical properties. However, corrosion and elemental release are some of the distinctive disadvantages shown by metals used as biomaterials [27-30]. Corrosion can be defined as a "physicochemical interaction (usually of an electrochemical nature) between a metal and its environment which results in changes in the properties of the metal and which may often lead to impairment of the function of the metal, the environment, or the technical system of which these form a part" [31]. Saliva, as it contains bacteria, viruses, yeast, fungi and their products [32] may cause corrosion of orthodontic appliances. House et al. [33] classified the corrosion types observed in metallic biomaterials as uniform attack, pitting and crevice corrosion, galvanic corrosion, intergranular corrosion, fretting corrosion, corrosion fatigue, and microbiologically-influenced corrosion. The alloys used in orthodontic appliances rely on the formation of a passive oxide film to resist corrosion, but this layer is not infallible since it can be disrupted by chemical and mechanical attack [33].

Elemental release is influenced by the composition of the alloy. Zinc and copper are released from stainless steel due to the electronic structure of such elements at the atomic level and the phase structure of the alloy [30]. Chromium is also released by this alloy [14,34]. Nickel, a known allergen, is released by nickel-titanium and stainless steel orthodontic alloys [35-39]. Previous research showed high concentrations of nickel in the saliva and oral mucosa of patients wearing orthodontic appliances [40-42]. Oral signs and symptoms of nickel allergy include burning sensation, gingival hyperplasia, angular cheilitis, erythema multiforme, stomatitis, popular perioral rash, and loss of taste, as well as others [43]. In addition, orthodontic treatment carried out with fixed appliances provides a unique environment for colonization of microorganisms since orthodontic devices contain morphological irregularities that make it difficult for patients to maintain adequate oral hygiene [44]. 
Additional challenges are encountered when using metals as orthodontic biomaterials. Friction control is a major challenge since a percentage of the applied force is dissipated to overcome friction, while the remaining percentage is transmitted to the supporting structures to induce tooth movement [45]. Therefore, the total force is determined by the force to move a tooth and the force needed to overcome friction between the bracket and the wire [46,47]. A high friction coefficient is needed in case of anchorage, whereas for retraction of teeth and space closure, a low friction coefficient is desirable [48]. Friction coefficients differ among those materials used for fabricating orthodontic brackets and wires, which in turn, can modify treatment times according to the bracket/wire combination used [49].

Many approaches have been investigated to overcome the above-mentioned disadvantages. Coating the surface of orthodontic metallic wires using various techniques and materials, as well as modifying the surface of wires and brackets, are among those strategies developed to improve both mechanical and biological properties of metals used in orthodontics. Therefore, the main objective of this paper is to review coating techniques and materials as well as different surface treatments performed on metallic orthodontic materials.

\section{Coating Techniques and Materials}

The application of coatings is one of the approaches that is available to modify the surface of materials. Various coating techniques and materials have been used with the objective of improving surface properties. However, some problems with coatings have arisen, mainly the delamination or wear of the coating [1]. Nonetheless, investigations continue to find suitable materials and techniques to improve the properties of metallic biomaterials. To date, this approach has been used mainly in vitro to further evaluate coating behavior, biological properties of coated substrates, and mechanical characteristics of both coatings and substrates. For instance, Bandeira et al. [50] used a coating technology known as an electrostatic powder technique to apply epoxy paint to NiTi wires. The purpose was to compare friction between coated and uncoated wires. It was found that coated wires showed reduced friction when compared to uncoated ones. Regarding biological properties, Kobayashi et al. [51] deposited a diamond-like carbon coating on NiTi archwires to test in vitro whether nickel release could be reduced. This investigation concluded that there was a reduction in the concentration of nickel ions in physiological saline, which makes DLC non-cytotoxic in a corrosive environment. However, clinical approaches have also been tried. Demling et al. [52] coated stainless steel brackets with polytetrafluoroethylene (PTFE) and randomly placed them in the oral cavities of children for eight weeks to compare biofilm formation on those brackets vs. uncoated brackets. After this time, a significant reduction in biofilm formation was found in coated brackets.

Additional techniques and materials are addressed below. Figure 1 summarizes the classification of coating techniques for industrial use, some of which have been implemented in orthodontics to improve the surface properties of such materials. 
Figure 1. Classification of processes used for coating at the industrial level (extracted from Peláez-Vargas, A [53].)

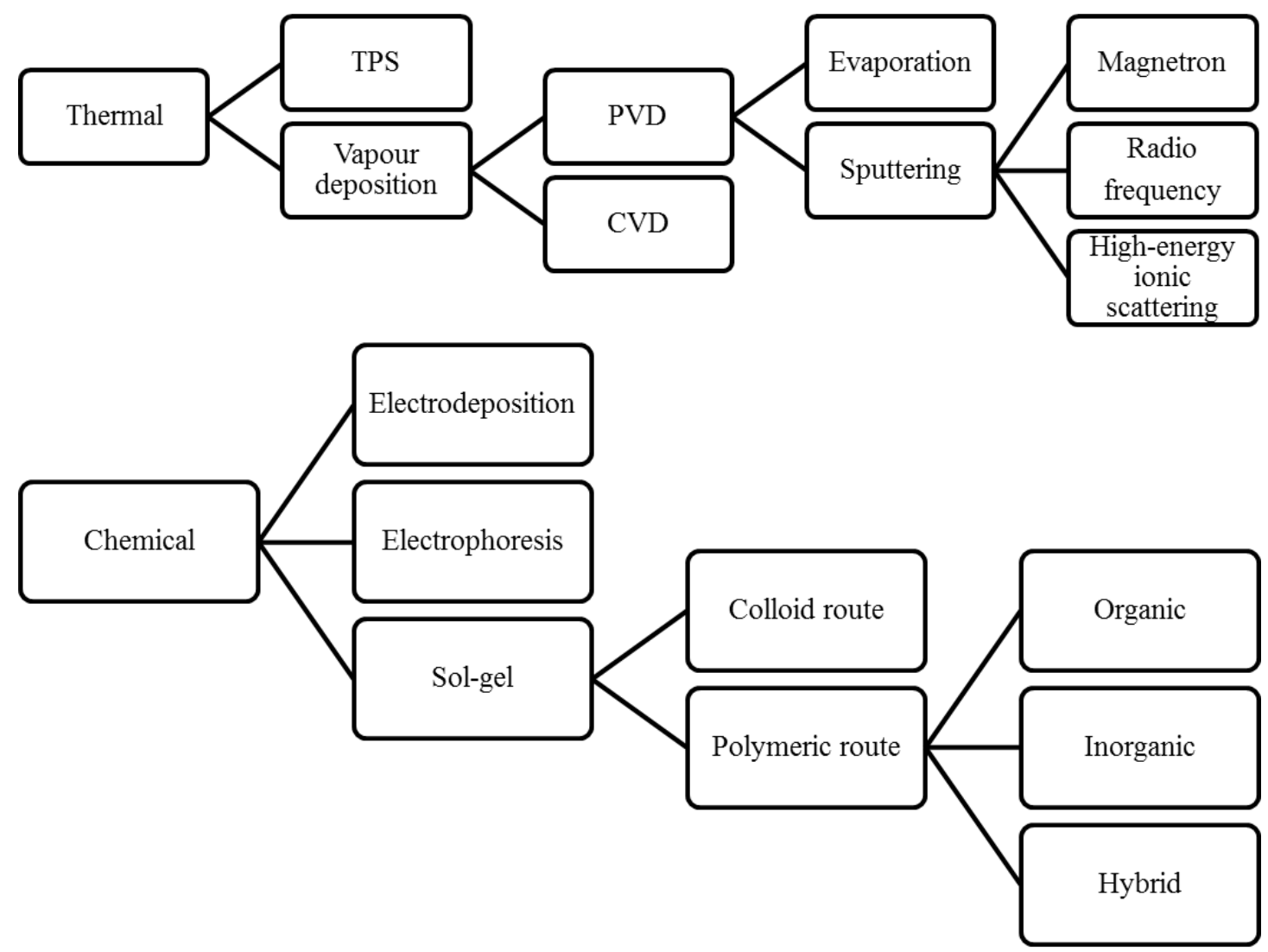

\subsection{Thermal Methods}

\subsubsection{Thermal Plasma Spray (TPS)}

This is a process in which finely ground metallic and non-metallic materials are deposited on a substrate in a molten or semi molten state. This technology is based on direct-current-arc or radiofrequency inductively coupled plasma (RF-ICP) discharge, which provides high temperatures that, in turn, allow melting of any material [54]. Plasma spray allows for high deposition rates ( $80 \mathrm{~g} / \mathrm{min})$, thick deposits, and low costs. Further, coatings achieved by this technique possess a rough surface that is suitable for bone growth, which is desirable for orthopedic applications [55]. Investigations on the use of this technique on metallic substrates, some of which can be used in implant dentistry, are reported [56-58]; however, its use has not been reported in the field of orthodontics to date.

\subsubsection{Chemical Vapor Deposition (CVD)}

This technique involves the flowing of a precursor gas into a chamber that contains one or more heated objects to be coated. Some chemical reactions take place on and near the hot surfaces, which results in the deposition of a thin film on the surface. The production of chemical by-products and their further exhaustion out of the chamber along with unreacted precursor gases accompanies the process. CVD has distinctive advantages: the films obtained with this technique are conformal (film thickness 
on the sidewalls is comparable to thickness on the top), a wide variety of materials can be applied and they can be deposited with a high level of purity, and it also presents high deposition rates. Its main disadvantage lies in the properties of the precursors, since they need to be volatile at near-room temperatures, which is non-trivial for a great number of elements. Other drawbacks include the fact that precursors can be toxic, explosive, expensive, corrosive, the by-products can be hazardous, and films need to be deposited at elevated temperatures, which restricts the types of materials that can be coated [59]. CVD has been used in endodontics to coat NiTi files [60,61] and in the coating of burs used in dentistry $[62,63]$. The use of this technology for coating metallic substrates in orthodontics has not been reported.

\subsubsection{Physical Vapor Deposition (PVD)}

This process consists of atomic deposition procedures in which a material is vaporized from solid or liquid sources in the form of atoms or molecules and transported in the form of vapor through a vacuum or low-pressure gaseous (plasma) environment to a substrate, where it finally condenses. This technique is suitable for depositing films in the range of a few nanometers to thousands of nanometers, for multilayer coating, graded composition deposits, very thick deposits, and freestanding structures [64]. Ryu et al. [65] used this method to apply coatings based on silver (Ag)-platinum (Pt) alloys to orthodontic stainless steel appliances to test their antimicrobial properties. They concluded that Ag-Pt coatings provide good antimicrobial activity during active orthodontic treatment. Krishnan et al. [66] coated beta titanium orthodontic archwires with titanium aluminum nitride (TiAlN) and tungsten carbide/carbon (WC/C) using PVD and evaluated frictional properties, surface morphology, and load deflection rate. They found that $\mathrm{WC} / \mathrm{C}$ archwires demonstrated reduced frictional properties, better surface characteristics, and low load deflection rate compared with TiAlN and uncoated archwires. In addition, Krishnan et al. [67] performed electrochemical corrosion behavior and surface analyses, mechanical testing, microstructure, elemental release and toxicology evaluations of TiAlN and $\mathrm{WC} / \mathrm{W}$ coatings on beta titanium orthodontic archwires and concluded that TiAlN shows better resistance to fluoride corrosive effects on this type of archwire. Physical vapor deposition can be divided into evaporation and physical sputtering.

\subsubsection{Evaporation}

Evaporation is the simplest physical vapor deposition method and has been proven useful for deposition of elemental films. This process is carried out in a vacuum system in which a material is heated to temperatures near its fusion or sublimation point $[68,69]$. Tripi et al. [60] used this technique for coating endodontic Ni-Ti files. The use of this technique to coat orthodontic metallic materials has not been reported in the literature.

\subsubsection{Physical Sputtering}

This technique involves the vaporization of atoms or molecules from a solid surface by momentum transfer from bombarding energetic atomic-sized particles. These particles are ions of a gaseous 
material accelerated in an electric field [64,68]. Physical sputtering can be divided into a number of methods, including radiofrequency (RF) magnetron sputtering and high-energy ionic scattering. Radiofrequency (RF) Magnetron Sputtering Method

This process removes surface atoms from a solid cathode (target) by bombarding it with positive ions from an inert gas discharge and deposits them on the surface to form a thin film. Substrates are placed in a vacuum chamber and are pumped down to a prescribed pressure process. Sputtering starts when a negative charge is applied to the target material, causing plasma or glow discharge. Positively-charged gas ions generated in the plasma region are attracted to the negatively-biased target plate at a very high speed rate. This collision creates a momentum transfer and ejects atomically sized particles from the target. These particles are deposited as a thin film onto the surface of substrates [70]. Shah et al. used this method to apply photocatalytic $\mathrm{TiO}_{2}$ to stainless steel orthodontic brackets in order to assess the antiadherent and antibacterial properties of such compounds against Lactobacillus acidophilus. Photocatalytic $\mathrm{TiO}_{2}$ demonstrated antibacterial and antiadherent properties; therefore, these authors also recommended it as a surface modification material to prevent developing dental plaque during active orthodontic treatment [70]. Ozeki et al. [71] coated NiTi alloy plates with hydroxyapatite, alumina, and titanium using this method to alleviate the effects of nickel allergy from NiTi alloy implants. Ozeki et al. [72] used this technique to coat NiTi orthodontic wires with titanium to evaluate the deterioration of the superelasticity of such wires and concluded that this coating method has potential for application in the orthodontic field. Surmenev et al. [73] used this technique to deposit calcium phosphate on NiTi substrates to assess nickel release. They found that nickel release from this alloy decreased when a thin layer of such a compound was applied.

\subsection{Chemical Methods}

\subsubsection{Electrodeposition}

In this technique, the substrate to be coated is made the negative electrode or cathode in a cell that contains an electrolyte, which must allow the passage of an electrical current. The electrolyte is usually a solution in water of a salt of the metal to be deposited and is maintained at a controlled temperature. The electrical circuit is completed by the anode, which is generally made of the metal to be deposited, and is located a short distance from the cathode. When a direct, low voltage current is applied, positively-charged ions in the electrolyte move toward the cathode where they undergo conversion to metal atoms and deposit on the cathode [74]. Investigations carried out in this area are in vitro in nature, but results are promising enough to incorporate some of these treatments into orthodontic practice. Redlich et al. [75] used electrodeposition to coat orthodontic archwires to reduce friction. The coating is based on a Ni film impregnated with inorganic fullerene-like nanospheres of tungsten disulphide. Their results showed a significant reduction in friction in coated vs. uncoated archwires. Samorodnitzky-Naveh et al. [76] tested inorganic fullerene-like tungsten disulfide (IF-WS 2 ) nanoparticles in vitro using electrodeposition to coat NiTi substrates in order to reduce friction and found a substantial reduction that might result in multiple applications. Zein El Abedin et al. [77] electroplated tantalum on NiTi alloys and evaluated corrosion behavior in $3.5 \% \mathrm{NaCl}$ solutions. Coated samples showed better corrosion resistance than uncoated alloys. Qiu et al. [78] used 
electrodeposition to apply hydroxyapatite and hydroxyapatite/zirconia composite coatings on NiTi alloys with the goal of assessing corrosion resistance. It was found that corrosion resistance significantly improved in a simulated body fluid after application of such a coating.

\subsection{Sol-Gel Method}

This process is a chemical method that allows the synthesis of glass, glass/ceramic and ceramic materials at temperatures much lower than other methods like CVD, PVD, or plasma spray and a variety of shapes, such as monoliths or nanospheres, among others, may be obtained $[53,79,80]$. The sol-gel method (Figure 2) requires the presence in solution of species that undergo polymerization reactions, leading to the formation of a gelatinous network, which can be dried and densified to the required product. Two routes can be used for the formation of such species. The first route involves the use of alkoxides, in which an organic solvent (typically alcohol) is required to act as a mutual solvent for the organometallic starting compound and the water necessary for hydrolysis. The second route involves the use of aqueous solutions, in which colloidal-size particles are formed in an aqueous medium from ionic species using the principles of colloidal chemistry [81]. These methods have their greatest potential in thin organic films and coatings [82].

Figure 2. Sol-gel processing.

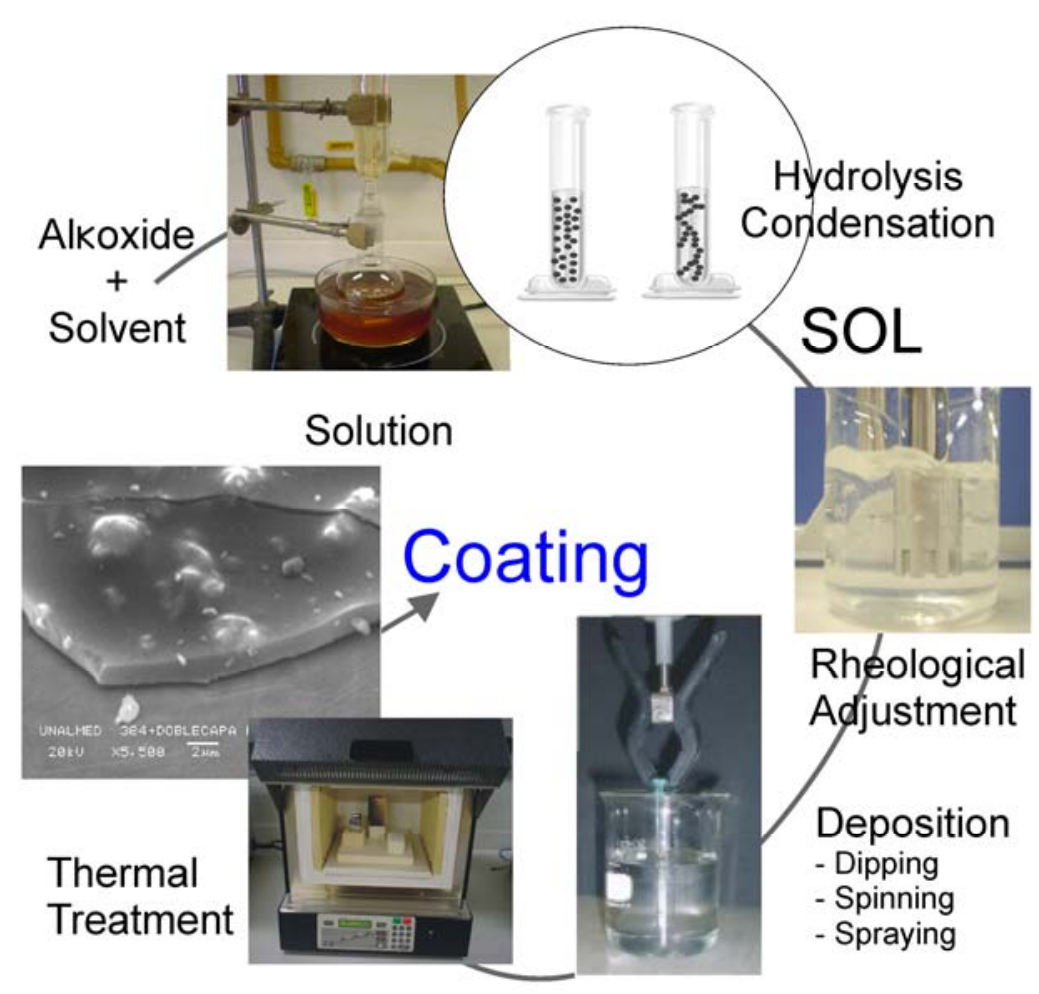

Chun et al. [83] applied photocatalytic titanium oxide $\left(\mathrm{TiO}_{2}\right)$ to stainless steel orthodontic wires using this method to evaluate its antibacterial and antiadherent properties. The results of their investigation showed that photocatalytic $\mathrm{TiO}_{2}$ may be used to prevent the development of dental plaque during orthodontic treatment. Rendón et al. [84] coated stainless steel orthodontic archwires with a glass using this method to evaluate friction between ceramic brackets and coated vs. uncoated archwires, since high friction coefficients are found between ceramic brackets and stainless steel 
archwires. It was found that a reduction in friction was not observed when coated archwires were slid against monocrystalline sapphire ceramic brackets and the authors concluded that a glass coating using the sol-gel method is not suitable to reduce friction between AISI 304 stainless steel archwires and ceramic brackets.

\section{Surface Modification}

Surface modification is aimed at improving surface properties of metallic materials. Horiuchi et al. [85] modified the surface of TiNi substrates through an electrolytic treatment to thicken the oxide film followed by heat treatment to induce crystallization of the oxide surface film in order to examine antibacterial effect. The amorphous oxide film was successfully modified. It was concluded that, after illumination with UVA light, photocatalytic activity was confirmed in treated TiNi alloy and an antibacterial effect was observed.

Ion implantation is another method used to modify the surface of materials. It consists of a low temperature process in which ions penetrate the surface of a material and modify it instead of coating it [86]. This technique has been used in orthodontics for different purposes. Teflon has been reported in the literature as one of the widest used materials to coat orthodontic appliances. De Franco et al. [87] used Teflon to coat stainless steel ligatures and compared frictional resistance between such ligatures and elastomeric ones. They used several archwire/bracket combinations and found that Teflon-coated stainless steel ligatures reduce friction between archwires and brackets. Neumann et al. [88] modified the surface of NiTi, beta titanium and stainless steel wires using polytetrafluorethylene (Teflon) by ion implantation with the objective of assessing corrosion resistance and mechanical endurance. This treatment prevented corrosion of the wires but Teflon was peeled off from the surface after mechanical testing. Husmann et al. [89] investigated force loss due to friction by ion implantation of Teflon on titanium alloy, beta-titanium, and stainless steel archwires. The main conclusion drawn from this investigation was that such coating significantly reduced frictional loss. A similar conclusion was drawn by Farronato et al. [90] in their study conducted to evaluate resistance to sliding of Teflon-coated archwires against different passive and active self-ligating brackets. A diamond-like carbon (DLC) coating was deposited on NiTi and stainless steel wires using the plasma-based ion implantation/deposition (PBIID) method to test friction and other mechanical properties, like hardness and elastic modulus. This study concluded that DLC could be successfully deposited by the PBIID method, there was a reduction in frictional force when this coat was present, and the DLC had a higher hardness value than untreated substrates [91]. A similar investigation was carried out to test DLC deposited on stainless steel orthodontic brackets using the PBIID method. The authors found a significant reduction in friction after application of the DLC [92].

\section{Conclusions}

Orthodontic surface treatment is an important area of active research. A myriad of materials and techniques have been implemented to modify the surfaces of dental materials. However, today only a few are being used in clinical orthodontics, especially in areas such as friction control and reduction of bacterial adhesion. In the last few years, multidisciplinary research has favored closing the gap that has existed between material surface engineering and clinical practice. Consequently, more new products 
have been introduced and have had a favorable impact in terms of reduction in biological and financial costs and in treatment time.

\section{Acknowledgments}

This work was supported by Universidad Cooperativa de Colombia (CONADI) and Universidad Nacional de Colombia (DIME).

\section{References}

1. Park, J.B.; Kim, Y.K. Metallic Biomaterials. In The Biomedical Engineering Handbook, 2nd ed.; Bronzino, J.D., Ed.; CRC Press LLC: Boca Raton, FL, USA, 2000.

2. García, C. Bioactivación de metales de uso ortopédico mediante recubrimientos producidos por sol-gel. Ph.D. Thesis, Universidad Nacional de Colombia, Medellín, Colombia, 2004

3. Brantley, W.A.; Eliades, T. Orthodontic Materials: Scientific and Clinical Aspects; Thieme: New York, NY, USA, 2001.

4. Albrektsson, T.; Zarb, G.; Worthington, P.; Eriksson, A.R. The long-term efficacy of currently used dental implants: A review and proposed criteria of success. Int. J. Oral Maxillofac. Implants 1986, 1, 11-25.

5. Palmquist, A.; Omar, O.M.; Esposito, M.; Lausmaa, J.; Thomsen, P. Titanium oral implants: Surface characteristics, interface biology and clinical outcome. J. R. Soc. Interface 2010, 7, S515-S527.

6. El-Zohairy, M.A.; Mostafa, A.; Amin, A.; Abd El-Fattah, H.; Khalifa, S. Mandibular reconstruction using pectoralis major myocutaneous flap and titanium plates after ablative surgery for locally advanced tumors of the oral cavity. J. Egypt Natl. Canc. Inst. 2009, 21, 299-307.

7. Lethaus, B.; Kessler, P.; Boeckman, R.; Poort, L.J.; Tolba, R. Reconstruction of a maxillary defect with a fibula graft and titanium mesh using CAD/CAM techniques. Head Face Med. 2010, 6,16 .

8. Stoetzer, M.; Rana, M.; von See, C.; Eckardt, A.M.; Gellrich, N.-C. Reconstruction of defects of maxillary sinus wall after removal of a huge odontogenic lesion using prebended 3D titanium-mesh and CAD/CAM technique. Head Face Med. 2011, 7, 21.

9. Nakajima, H.; Okabe, T. Titanium in dentistry: Development and research in the USA. Dent. Mater. J. 1996, 15, 77-90.

10. Ferreira, M.A.; Luersen, M.A.; Borges, P.C. Nickel-titanium alloys: A systematic review. J. Orthod. 2012, 17, 71-82.

11. Parvizi, F.; Rock, W.P. The load/deflection characteristics of thermally activated orthodontic archwires. Eur. J. Orthod. 2003, 25, 417-421.

12. ASTM F136-12a Standard Specification for Wrought Titanium-6Aluminum-4Vanadium ELI (Extra Low Interstitial) Alloy for Surgical Implant Applications (UNS R56401). Available online: http://www.astm.org/Standards/F136.htmn (accessed on 19 December 2012).

13. ASTM F67-06 Standard Specification for Unalloyed Titanium, for Surgical Implant Applications (UNS R50250, UNS R50400, UNS R50550, UNS R50700). Available online: http://www.astm.org/Standards/F67.htm (accessed on 19 December 2012). 
14. Sfondrini, M.F.; Cacciafesta, V.; Maffia, E.; Massironi, S.; Scribante, A.; Alberti, G.; Biesuz, R.; Klersy, C. Chromium release from new stainless steel, recycled and nickel-free orthodontic brackets. Angle Orthod. 2009, 79, 361-367.

15. Kohl, R. Metallurgy in orthodontics. Angle Orthod. 1964, 34, 37-52.

16. Roach, M. Base metal alloys used for dental restorations and implants. Dent. Clin. North Am. 2007, 51, 603-627.

17. Yoo, Y.R.; Jang, S.G.; Oh, K.T.; Kim, J.G.; Kim, Y.S. Influences of passivating elements on the corrosion and biocompatibility of super stainless steels. J. Biomed. Mater. Res. B 2008, 86, 310-320.

18. Anusavice, K.J. Phillips Ciencia de los Materiales Dentales, 11th ed.; Elsevier España: Madrid, Spain, 2004.

19. Izquierdo, P.P.; de Biasi, R.S.; Elias, C.N.; Nojima, L.I. Martensitic transformation of austenitic stainless steel orthodontic wires during intraoral exposure. Am. J. Orthod. Dentofacial. Orthop. 2010, 138, doi:10.1016/j.ajodo.2010.05.015.

20. Kocijan, A.; Conradi, M. The corrosion behaviour of austenitic and duplex stainless steels in artificial body fluids. Mater. Technol. 2010, 44, 21-24.

21. Cardarelli, F. Materials Handbook: A Concise Desktop Reference, 2nd ed.; Springer: London, UK, 2008.

22. Craig, H. Stress Corrosion—New Approaches; ASTM International: West Conshohocken, PA, USA, 1976.

23. Dionicio Padilla, E. Aplicaciones de los aceros inoxidables. Rev. Inst. Investig. Fac. Minas. Metal Cienc. Geogr. 1999, 2, 11-21.

24. Mistakidis, I.; Gkantidis, N.; Topouzelis, N. Review of properties and clinical applications of orthodontic wires. Hell. Orthod. Rev. 2011, 14, 45-66.

25. Oh, K.T.; Choo, S.U.; Kim, K.M.; Kim, K.N. A stainless steel bracket for orthodontic application. Eur. J. Orthod. 2005, 27, 237-244.

26. Soratur, S. Essentials of Dental Materials; Jaypee: New Delhi, India, 2002.

27. Costa, M.T.; Lenza, M.A.; Gosch, C.S.; Costa, I.; Ribeiro-Dias, F. In vitro evaluation of corrosion and cytotoxicity of orthodontic brackets. J. Dent. Res. 2007, 86, 441-445.

28. Edie, J.W.; Andreasen, G.F.; Zaytoun, M.P. Surface corrosion of nitinol and stainless steel under clinical conditions. Angle Orthod. 1981, 51, 319-324.

29. Kim, H.; Johnson, J.W. Corrosion of stainless steel, nickel-titanium, coated nickel-titanium, and titanium orthodontic wires. Angle Orthod. 1999, 69, 39-44.

30. Schmalz, G. Arenholt-Bindslev, D. Biocompatibility of Dental Materials; Springer: Berlin, Germany, 2009.

31. Javaherdashti, R. Microbiologically Influenced Corrosion. An Engineered Insight; Springer: London, UK, 2008.

32. Anandkumar, B.; Maruthamuthu, S. Molecular identification and corrosion behaviour of manganese oxidizers on orthodontic wires. Curr. Sci. 2008, 94, 891-896.

33. House, K.; Sernetz, F.; Dymock, D.; Sandy, J.R.; Ireland, A.J. Corrosion of orthodontic appliances - Should we care? Am. J. Orthod. Dentofacial Orthop. 2008, 133, 584-592. 
34. Matos de Souza, R.; Macedo de Menezes, L. Nickel, chromium and iron levels in the saliva of patients with simulated fixed orthodontic appliances. Angle Orthod. 2008, 78, 345-350.

35. Ehrnrooth, M.; Kerosuo, H. Face and neck dermatitis from a stainless steel orthodontic appliance. Angle Orthod. 2009, 79, 1194-1196.

36. Huang, H.H.; Chiu, Y.H.; Lee, T.H.; Wu, S.C.; Yang, H.W.; Su, K.H.; Hsu, C.C. Ion release from NiTi orthodontic wires in artificial saliva with various acidities. Biomaterials 2003, 24, 3585-3592.

37. Jacobsen, N.; Hensten-Pettersen, A. Changes in occupational health problems and adverse patient reactions in orthodontics from 1987 to 2000. Eur. J. Orthod. 2003, 25, 591-598.

38. Kanerva, L.; Sipiläinen-Malm, T.; Estlander, T.; Zitting, A.; Jolanki, R.; Tarvainen, K. Nickel release from metals, and a case of allergic contact dermatitis from stainless steel. Contact Dermatitis 1994, 31, 299-303.

39. Noble, J.; Ahing, S.I.; Karaiskos, N.E.; Wiltshire, W.A. Nickel allergy and orthodontics, a review and report of two cases. Br. Dent. J. 2008, 204, 297-300.

40. Ağaoğlu, G.; Arun, T.; Izgi, B.; Yarat, A. Nickel and chromium levels in the saliva and serum of patients with fixed orthodontic appliances. Angle Orthod. 2001, 71, 375-379.

41. Amini, F.; Borzabadi Farahani, A.; Jafari, A.; Rabbani, M. In vivo study of metal content of oral mucosa cells in patients with and without fixed orthodontic appliances. Orthod. Craniofac. Res. 2008, 11, 51-56.

42. Petoumenou, E.; Arndt, M.; Keilig, L.; Reimann, S.; Hoederath, H.; Eliades, T.; Jäger, A.; Bourauel, C. Nickel concentration in the saliva of patients with nickel-titanium orthodontic appliances. Am. J. Orthod. Dentofacial Orthop. 2009, 135, 59-65.

43. Noble, J.; Ahing, S.I.; Karaiskos, N.E.; Wiltshire, W.A. Should I be concerned if a patient requiring orthodontic treatment has an allergy to nickel? J. Can. Dent. Assoc. 2008, 74, 897-898.

44. Balenseifen, J.W.; Madonia, J.V. Study of dental plaque in orthodontic patients. J. Dent. Res. 1970, 49, 320-324.

45. Da Cunha, A.C.; Marquezan, M.; Freitas, A.O.; Nojima, L.I. Frictional resistance of orthodontic wires tied with 3 types of elastomeric ligatures. Braz. Oral Res. 2011, 25, 526-530.

46. Angolkar, P.V.; Kapila, S.; Duncanson, M.G., Jr.; Nanda, R.S. Evaluation of friction between ceramic brackets and orthodontic wires of four alloys. Am. J. Orthod. Dentofacial Orthop. 1990, 98, 499-506.

47. Kapila, S.; Angolkar, P.V.; Duncanson, M.G., Jr.; Nanda, R.S. Evaluation of friction between edgewise stainless steel brackets and orthodontic wires of four alloys. Am. J. Orthod. Dentofacial Orthop. 1990, 98, 117-126.

48. Burrow, S.J., Friction and resistance to sliding in orthodontics: A critical review. Am. J. Orthod. Dentofacial Orthop. 2009, 135, 442-447.

49. Guerrero, A.P.; Guariza Filho, O.; Tanaka, O.; Camargo, E.S.; Vieira, S. Evaluation of frictional forces between ceramic brackets and archwires of different alloys compared with metal brackets. Braz. Oral Res. 2010, 24, 40-45.

50. Bandeira, A.M.; dos Santos, M.P.; Pulitini, G.; Elias, C.N.; da Costa, M.F. Influence of thermal or chemical degradation on the frictional force of an experimental coated NiTi wire. Angle Orthod. 2011, 81, 484-489. 
51. Kobayashi, S.; Ohgoe, Y.; Ozeki, K.; Hirakuri, K.; Aoki, H. Dissolution effect and cytotoxicity of diamond-like carbon coatings on orthodontic archwires. J. Mater. Sci. Mater. Med. 2007, 18, 2263-2268.

52. Demling, A.; Elter, C.; Heidenblut, T.; Bach, F.W.; Hahn, A.; Schwestka-Polly, R.; Stiesch, M.; Heuer, W. Reduction of biofilm on orthodontic brackets with the use of a polytetrafluoroethylene coating. Eur. J. Orthod. 2010, 32, 414-418.

53. Peláez-Vargas, A. Evaluación de la toxicidad in vitro, la adherencia y la nanotopografía de recubrimientos aplicados por sol-gel para implantes metálicos. Master's Thesis, National University of Colombia, Medellín, Colombia, 2005.

54. Fridman, A. Plasma Chemistry; Cambridge University Press: New York, NY, USA, 2008.

55. Chu, P.K. Plasma-treated biomaterials. IEEE Trans. Plasma Sci. 2007, 35, 181-187.

56. Junker, R.; Manders, P.J.; Wolke, J.; Borisov, Y.; Braceras, I.; Jansen, J.A. Loaded microplasmasprayed CaP-coated implants in vivo. J. Dent. Res. 2010, 89, 1489-1493.

57. Prymak, O.; Bogdansk, D.; Esenwein, S.A.; Köller, M.; Epple, M. NiTi shape memory alloys coated with calcium phosphate by plasma-spraying. Chemical and biological properties. Materialwiss. Werkstofftech. 2004, 35, 346-351.

58. Sun, L.; Berndt, C.C.; Gross, K. A.; Kucuk, A. Material fundamentals and clinical performance of plasma-sprayed hydroxyapatite coatings: A review. J. Biomed. Mater. Res. 2001, 58, 570-592.

59. Park, J.H.; Sudarshan, T.S. Chemical Vapor Deposition; ASM International: Materials Park, OH, USA, 2001.

60. Tripi, T.R.; Bonaccorso, A.; Condorelli, G.G. Fabrication of hard coatings on NiTi instruments. J. Endod. 2003, 29, 132-134.

61. Tripi, T.R.; Bonaccorso, A.; Rapisarda, E.; Tripi, V.; Condorelli, G.G.; Marino, R.; Fragalà, I. Depositions of nitrogen on NiTi instruments. J. Endod. 2002, 28, 497-500.

62. Borges, C.F.; Magne, P.; Pfender, E.; Heberlein, J. Dental diamond burs made with a new technology. J. Prosthet. Dent. 1999, 82, 73-79.

63. Lima, L.M.; Motisuki, C.; dos Santos-Pinto, L.; dos Santos-Pinto, A.; Corat, E.J. Cutting characteristics of dental diamond burs made with CVD technology. Braz. Oral Res. 2006, 20, $155-161$.

64. Mattox, D.M. Handbook of Physical Vapor Deposition Processing, 2nd ed.; Elsevier: Burlington, VT, USA, 2010.

65. Ryu, H.S.; Bae, I.H.; Lee, K.G.; Hwang, H.S.; Lee, K.H.; Koh, J.T.; Cho, J.H. Antibacterial effect of silver-platinum coating for orthodontic appliances. Angle Orthod. 2012, 82, 151-157.

66. Krishnan, V.; Ravikumar, K.K.; Sukumaran, K.; Kumar, K.J. In vitro evaluation of physical vapor deposition coated beta titanium orthodontic archwires. Angle Orthod. 2012, 82, 22-29.

67. Krishnan, V.; Krishnan, A.; Remya, R.; Ravikumar, K.K.; Nair, S.A.; Shibli, S.M.; Varma, H.K.; Sukumaran, K.; Kumar, K.J. Development and evaluation of two PVD-coated beta-titanium orthodontic archwires for fluoride-induced corrosion protection. Acta Biomater. 2011, 7, 1913-1927.

68. Cao, G.; Wang, Y. Nanostructures and Nanomaterials. Synthesis, Properties and Applications, 2nd ed.; World Scientific Publishing: Singapore, 2011. 
69. Vásquez, A.; Damborenea, J. Ciencia e Ingeniería de la Superficie de los Materiales Metálicos; CSIC-Dpto. de Publicaciones: Madrid, Spain, 2001.

70. Shah, A.G.; Shetty, P.C.; Ramachandra, C.S.; Bhat, N.S.; Laxmikanth, S.M. In vitro assessment of photocatalytic titanium oxide surface modified stainless steel orthodontic brackets for antiadherent and antibacterial properties against Lactobacillus acidophilus. Angle Orthod. 2011, 81, 1028-1035.

71. Ozeki, K.; Yuhta, T.; Aoki, H.; Fukui, Y. Inhibition of Ni release from NiTi alloy by hydroxyapatite, alumina, and titanium sputtered coatings. Biomed. Mater. Eng. 2003, 13, 271-279.

72. Ozeki, K.; Yuhta, T.; Aoki, H.; Asaoka, T.; Daisaku, T.; Fukui, Y. Deterioration in the superelasticity of Ti sputter coated on NiTi orthodontic wire. Biomed. Mater. Eng. 2003, 13, 355-362.

73. Surmenev, R.A.; Ryabtseva, M.A.; Shesterikov, E.V.; Pichugin, V.F.; Peitschm, T. Epple, M. The release of nickel from nickel-titanium (NiTi) is strongly reduced by a sub-micrometer thin layer of calcium phosphate deposited by rf-magnetron sputtering. J. Mater. Sci. Mater. Med. 2010, 21, 1233-1239.

74. Grainger, S.; Blunt, J. Engineering Coatings. Design and Application, 2nd ed.; Plastics Design Library: Cambridge, UK, 1998.

75. Redlich, M.; Gorodnev, A.; Feldman, Y.; Kaplan-Ashiri, I.; Tenne, R.; Fleischer, N.; Genut, M.; Feuerstein, N. Friction reduction and wear resistance of electro-co-deposited inorganic fullerene-like $\mathrm{WS}_{2}$ coating for improved stainless steel orthodontic wires. J. Mater. Res. 2008, 23, 2909-2915.

76. Samorodnitzky-Naveh, G.R.; Redlich, M.; Rapoport, L.; Feldman, Y.; Tenne, R. Inorganic fullerene-like tungsten disulfide nanocoating for friction reduction of nickel-titanium alloys. Nanomedicine (Lond.) 2009, 4, 943-950.

77. Zein El Abedin, S.; Welz-Biermann, U.; Endres, F. A study on the electrodeposition of tantalum on NiTi alloy in an ionic liquid and corrosion behaviour of the coated alloy. Electrochem. Commun. 2005, 7, 941-946.

78. Qiu, D.; Wang, A.; Yin, Y. Characterization and corrosion behavior of hydroxyapatite/zirconia composite coating on NiTi fabricated by electrochemical deposition. Appl. Surf. Sci. 2010, 257, 1774-1778.

79. Mackenzie, J.D.; Bescher, E.P. Physical properties of sol-gel coatings. J. Sol-Gel Sci. Technol. 2000, 19, 23-29.

80. Patil, K.R.; Hwang, Y.K.; Kim, M.J.; Chang, J.S.; Park, S.E. Preparation of thin films comprising palladium nanoparticles by a solid-liquid interface reaction technique. J. Colloid Interface Sci. 2004, 276, 333-338.

81. Cable, M.; Parker, J.M. High-Performance Glasses; Springer: New York, NY, USA, 1992.

82. Bach, H.; Krause, D. Thin Films on Glass; Springer: Berlin, Germany, 2003.

83. Chun, M.J.; Shim, E.; Kho, E.H.; Park, K.J.; Jung, J.; Kim, J.M.; Kim, B.; Lee, K.H.; Cho, D.L.; Bai, D.H.; et al. Surface modification of orthodontic wires with photocatalytic titanium oxide for its antiadherent and antibacterial properties. Angle Orthod. 2007, 77, 483-488. 
84. Rendón Arias, L.A.; Cano Correa, G.A.; peláez Vargas, A.; Jaramillo Vallejo, P.M.; García Garcia, C.; Góez, Y.M. Evaluación in vitro de la resistencia friccional entre brackets cerámicos y arcos de acero inoxidable con y sin recubrimiento vítreo aplicado por el método Sol-Gel. Rev. Fac. Odontol. Univ. Antioq. 2008, 20, 58-71.

85. Horiuchi, Y.; Horiuchi, M.; Hanawa, T.; Soma, K. Effect of surface modification on the photocatalysis of Ti-Ni alloy in orthodontics. Dent. Mater. J. 2007, 26, 924-929.

86. Narayan, R. Biomedical Materials; Springer: New York, NY, USA, 2009.

87. De Franco, D.J.; Spiller, R.E., Jr.; von Fraunhofer, J.A. Frictional resistances using Teflon-coated ligatures with various bracket-archwire combinations. Angle Orthod. 1995, 65, 63-72.

88. Neumann, P.; Bourauel, C.; Jager, A. Corrosion and permanent fracture resistance of coated and conventional orthodontic wires. J. Mater. Sci. Mater. Med. 2002, 13, 141-147.

89. Husmann, P.; Bourauel, C.; Wessinger, M.; Jäger, A. The frictional behavior of coated guiding archwires. J. Orofac. Orthop. 2002, 63, 199-211.

90. Farronato, G.; Maijer, R.; Caria, M.P.; Esposito, L.; Alberzoni, D.; Cacciatore, G. The effect of Teflon coating on the resistance to sliding of orthodontic archwires. Eur. J. Orthod. 2012, 34, 410-417.

91. Muguruma, T.; Iijima, M.; Brantley, W.A.; Mizoguchi, I. Effects of a diamond-like carbon coating on the frictional properties of orthodontic wires. Angle Orthod. 2011, 81, 141-148.

92. Muguruma, T.; Iijima, M.; Brantley, W.A.; Nakagaki, S.; Endo, K.; Mizoguchi, I. Frictional and mechanical properties of diamond-like carbon-coated orthodontic brackets. Eur. J. Orthod. 2011, doi:10.1093/ejo/cjr113.

(C) 2013 by the authors; licensee MDPI, Basel, Switzerland. This article is an open access article distributed under the terms and conditions of the Creative Commons Attribution license (http://creativecommons.org/licenses/by/3.0/). 